\title{
"Green farming" - a set of technologies of the future
}

\author{
E.M. Gusev* \\ FSBIS Institute of Water Problems of the Russian Academy of Sciences, Gubkina St., 3 119333, \\ Moscow, Russia
}

\begin{abstract}
The purpose of the work was to demonstrate the evolution of agricultural technologies, which leads to the orientation of agriculture towards the use of nature-like farming, using the example of the human civilization development. It was shown that in the XX century, the stage of development of soil cultivation technologies, associated with the transition from "gray" extensive technologies for managing natural resources, which were focused on momentary economic feasibility, to non-traditional farming technologies, began. It was demonstrated that a natural transition is currently taking place from the technology development strategy based on the principle of maximum entropy production by G. Ziegler, to the strategy of minimum entropy production by I. Prigozhin, which is based on the rationalization of the use of the planet's resources. It was confirmed that at the present stage humanity has approached the change of technologies from the extensive development and use of natural resources to rationalizing their use - "green farming", which is characterized by a more natural agricultural technology of soil cultivation; mulching its surface with plant residues which leads to a decrease in soil erosion and unproductive evaporation; minimizing soil compaction; reducing the need for irrigation; reducing the use of herbicides through the use of cover crops, etc.
\end{abstract}

\section{Introduction}

Living organisms and their communities on Earth, being dissipative structures [21], evolve at different stages of their development within the framework of two fundamental physical laws - Ziegler's principle of maximum entropy production [14, 30, 38] and Prigozhin's principle of minimum entropy production [19], the priority of which changes during the emergence, evolution and destruction of various biospheric structures. In [21, 27], the physical substantiation of the classical ecology laws by B. Commoner [11] is presented, which serve as a guideline for the creation of technologies for the use of natural resources by man, and it is also demonstrated that civilization in modern Holocene stage found itself in a situation obeying the action of Prigozhin's principle - a situation of necessity and inevitability of the rational use of available resources. This is typical for all areas of human activity, including agriculture and the associated water sector.

\footnotetext{
${ }^{*}$ Corresponding author: sowaso@yandex.ru
} 
Current sharp deterioration of the environment state caused by the increased consumption of natural resources by man, which also affected the safety of the existence of the very "crown of nature" on Earth, is due to the orientation of mankind in the previous Holocene period to the Ziegler's principle, which determines the intensified exploitation of the planet's resources due to the creation of so-called "gray" [33] (technosphere) technologies for natural resource management, focused on the momentary economic feasibility and philosophy of increase in consumption.

In this regard, as shown in [21] on the basis of the dissipative structures theory, humanity is doomed to transition due to natural homeostasis to non-traditional (naturebased, "green" [33]) technologies for managing natural resources, focused on the Prigozhin's strategy of minimum entropy production. The conclusion about the need to develop non-traditional technologies for managing natural resources is increasingly appearing in scientific literature (a number of works are given in [21]), in reports of international organizations [36, 37], at various conferences, symposia, working meetings (for example, the XII International Forum "Green economy ", May 21-23, 2018, RF, St. Petersburg). The emphasis is placed on the need to orient to the principles of "green economy" which represents a direction in economic science, within the framework of which it is assumed that the economy is a dependent component of the natural environment, within which it exists and is a part of it.

At the same time, such a sector of nature management as agriculture must satisfy the demand for food by increasing the efficiency of natural resources use with a simultaneous decrease in the occupied area. One of the central places in this paradigm is the optimization of the water resources use. But the main factor in the approach to sustainable intensification of agricultural production is "resource-saving (green) farming". Although the paradigm of green farming also touches upon the problems associated with irrigation, the main focus within its framework should be land reclamation and increasing yields in non-irrigation systems that are not associated with disruption of the natural circulation of the hydrological cycle.

In connection with the foregoing, the purpose of this work is to use the human civilization development as an example for demonstrating the evolution of agricultural technologies leading to the orientation of agriculture in the near future on the use of naturebased technologies, thereby confirming the theoretical substantiation of the inevitability of the so-called "green farming" using the example of a centuries-old biosphere experiment, actually set by nature itself.

\section{Methods and materials}

1. Justification of the inevitability of the "green economy" strategy development is based on the methods of the dissipative structures' theory [21], related to non-equilibrium thermodynamics. Let us explain the concept of dissipative structure, which plays an important role in the functioning analysis of organisms and supraorganismic systems. A dissipative structure (or dissipative system) is an open system that functions far from thermodynamic equilibrium, existing under the condition of diffusion (dissipation) of energy that the system receives from the outside. Examples of global dissipative structures are atmospheric circulation, ocean circulation, hydrological cycle and circulation of bioelements, which is sometimes called "life" [17]. Living organisms, their communities, including the human population, are also dissipative structures.

Methods of non-equilibrium thermodynamics, which are applicable to any dissipative systems (which include living systems), make it possible to analyze the ecological processes associated with various technologies of nature management and to show the inevitability of the use of nature-based technologies by the human population. 
2. The results of the analysis of a large number of literary sources devoted to the evolution of farming technologies on the planet during the period of human existence served as a confirmation of the conclusion obtained in paragraph 1 about the inevitability of a "green economy".

3. To assess the prospects for the use of non-traditional agrotechnical technologies in agriculture of the Russian Federation, physical and mathematical modeling of heat and water exchange in the soil - vegetation - atmosphere system was used, which made it possible to reproduce the processes of formation of water regime and grain yield when different methods of soil cultivation are applied on the territory of the steppe and foreststeppe zones of the European part of Russia.

\section{Results}

\subsection{Theoretical foundations of "green farming"}

It is shown in [21] that the evolution of dissipative structures on Earth occurs in accordance with biospheric crises due to either external causes or internal logic of the structures' development, when the extensive path of their development leads to a dead end. As a result of reaching such a bifurcation point, the crisis is resolved by the emergence of new structures, giving way to the next stage of evolution (Fig. 1).

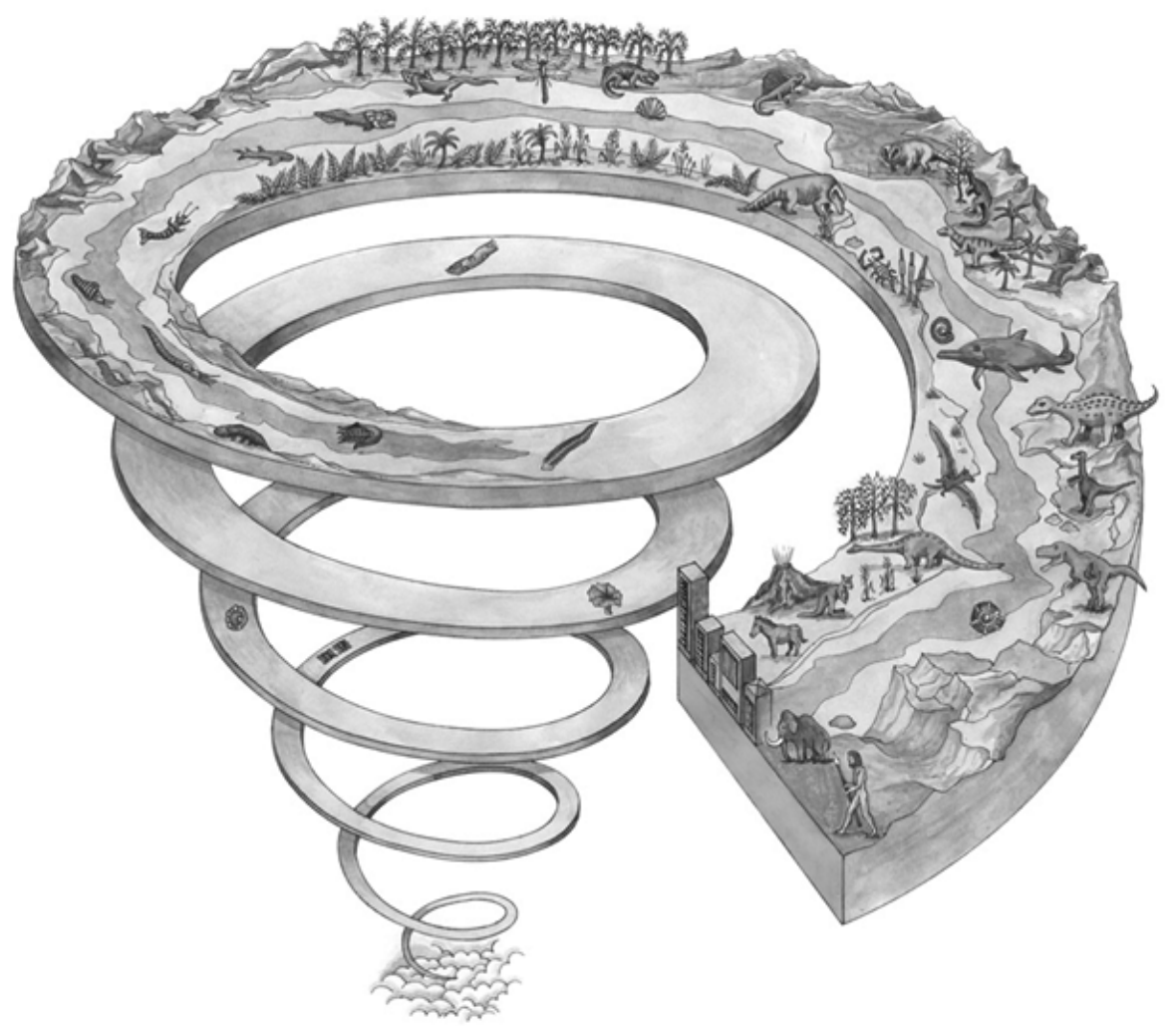

Fig. 1. Spiral of the Earth's development and the evolution of life on it, Source: https://jurassiccoast.org/wp-content/uploads/2015/08/spiral-diagram-end-1.jpg.

The evolution direction of the emerging structures determines the principle of maximum 
entropy production by G. Ziegler [38]. In accordance with it, those biological species that best utilize the available incoming energy for growth and existence will increase their numbers and spatial distribution, which leads to a further increase in the flow of energy through the system. In this case, the dissipation of energy, i.e. the entropy production by the system, increase accordingly. During this period, the most competitive structures are formed (in particular, human civilization during the Holocene).

When the available energy has been used up, fast evolutionary changes are replaced by relatively slow optimization processes of homeostasis of emerging structures, which lead to a decrease in losses when converting the incoming energy into such a form that can be used by developing structures. Accordingly, the minimization of energy dissipation and hence the production of entropy begins. In this case, the principle of minimum entropy production by I. Prigozhin [19] begins to operate, i.e. structures are beginning to make more rational use of available resources. But such a strategy was implemented by the Nature earlier (in the absence of man) on the basis of the biota ability to regulate and stabilize the biosphere of the planet, which developed in the process of evolution. The presence of a very large number of "soft" negative feedbacks leads to the fact that nature without Mind leads to a minimum of the destructive processes' intensity as a whole on the planet. Therefore, at this stage of evolution, B. Commoner's empirical law of ecology becomes valid: nature knows best. Of course, this does not mean that a person does not need to think when creating new technologies for the use of natural resources. This law means that when developing such technologies, it is necessary to focus as much as possible on natural or nature-like processes. This strategy determines the direction of all types of human activity, including agriculture and, in parallel, water management.

In agriculture, this strategy is often referred to as "green farming". This type of farming is characterized primarily by a more economical method of soil cultivation ("no-till", "striptill") and a number of other specific features: reduction or absence of moldboard plowing, minimization of soil cover disturbance by agricultural machines, the use of cover crops or green manure ( plants grown in order to improve the soil structure and suppress the growth of weeds) and the obligatory soil covering with a layer of vegetative mulch in order to preserve soil moisture and reduce soil erosion. Generally speaking, bare soil is unnatural for the biosphere and vegetation is the "natural mulch" of the Earth.

\subsection{The evolution of technologies in agriculture during the Holocene: from "gray" to "green"}

The above theoretical conclusions are confirmed by a kind of centuries-old "experiment" carried out by the biosphere as part of the farming technologies' evolution carried out by human civilization and which began on the planet more than 10 thousand years ago. Based on the studies of this evolution (some of the works devoted to such studies are given in [20]), it can be shown how during the development of agriculture there was a turn from the tillage technologies and the use of irrigation, based on the principle of maximum entropy production by G. Ziegler, to technologies based on the principle of minimum entropy production by I. Prigozhin.

At the beginning of the farming technologies evolution, there were practically no special tillage tools at all. The grains were sown into soil holes with a sharpened stick. In fact, the evolution of tillage methods began with this first primitive no-till technology. This is how primitive cultures all over the world acted: the Incas of the Andes in South America, the Sumerians, the ancient Egyptians and other nations (Fig. 2). Weed control and soil fertilization were combined in time: wild vegetation at the site of the future field was liquidated by slash-and-burn method or simply by fire and the remaining ash was used as fertilizer. 


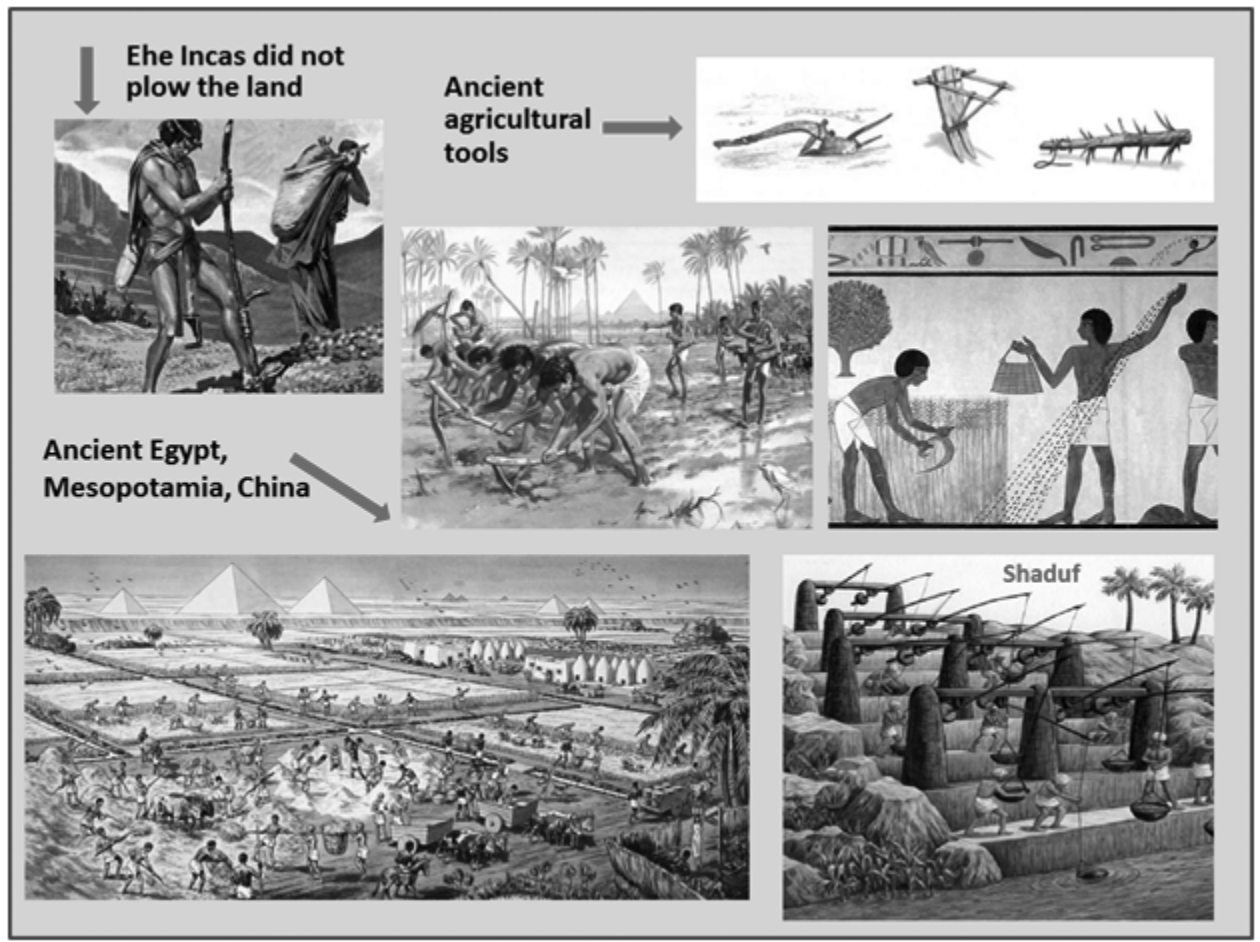

Fig. 2. Ancient agriculture.

The next technological step in agriculture was the use of socha (wooden plow for light plough without a mouldboard) using the muscle energy of humans or animals. Its use made it possible to create furrows instead of fossa, which increased the productivity of soil cultivation, although the technology of agrocenoses cultivation has practically not changed.

However, the population growth on the planet required both an increase in the area of agricultural land and an increase in crop yields. The main solution to this problem came with the emergence of such agricultural technology as plow tillage (Fig. 3).
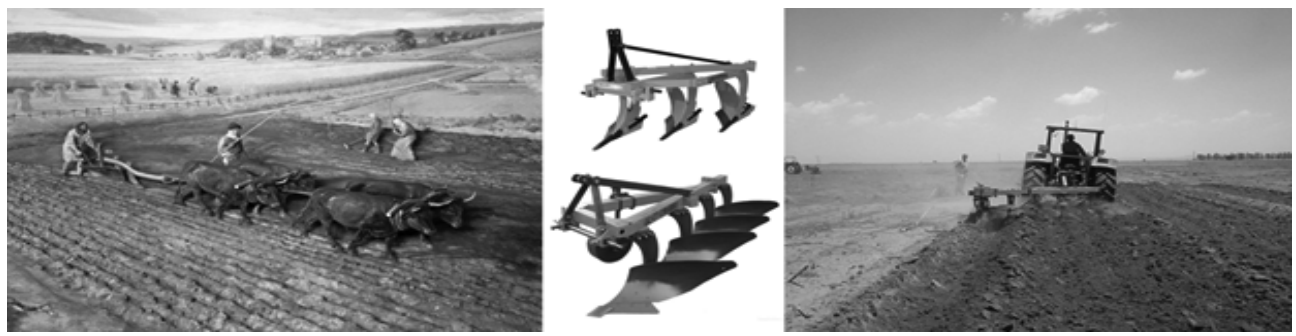

Fig. 3. Plow farming.

Generally speaking, the iron plow dates back to $\mathrm{BC}$, but it had little in common with the modern plow. Gradually, the design of plows became more complicated and at the end of the 18th century in Europe, a moldboard plow appeared that turned the soil at an angle of $135^{\circ}$ (Fig. 3) and was an effective mean of weed control. At first, deep plowing contributed to the preservation of moisture in the soil, the destruction of weeds and the enhancement of the vital activity of beneficial microorganisms. Having defeated creeping wheatgrass that spread throughout Europe, the modern plow saved it from hunger and poverty, by virtue of which it has become synonymous with "modern" agriculture. The 
colonial policy of European countries led to the transfer of the plow to other continents of Earth, due to which it became a universal soil cultivation tool.

Since increasing yields continued to be the most important goal of agricultural production, this stage of farming technologies evolution logically developed according to the Ziegler's principle of maximum entropy production. Tilling the soil with a plow required more and more energy costs. Tractors appeared, which power, width of the plow and the depth of plowing were constantly increasing. Additional tillage operations were included. Accordingly, the energy dissipation also increased that means an increase in the entropy production in the agricultural production system. All that has been said is illustrated in Fig. 4.

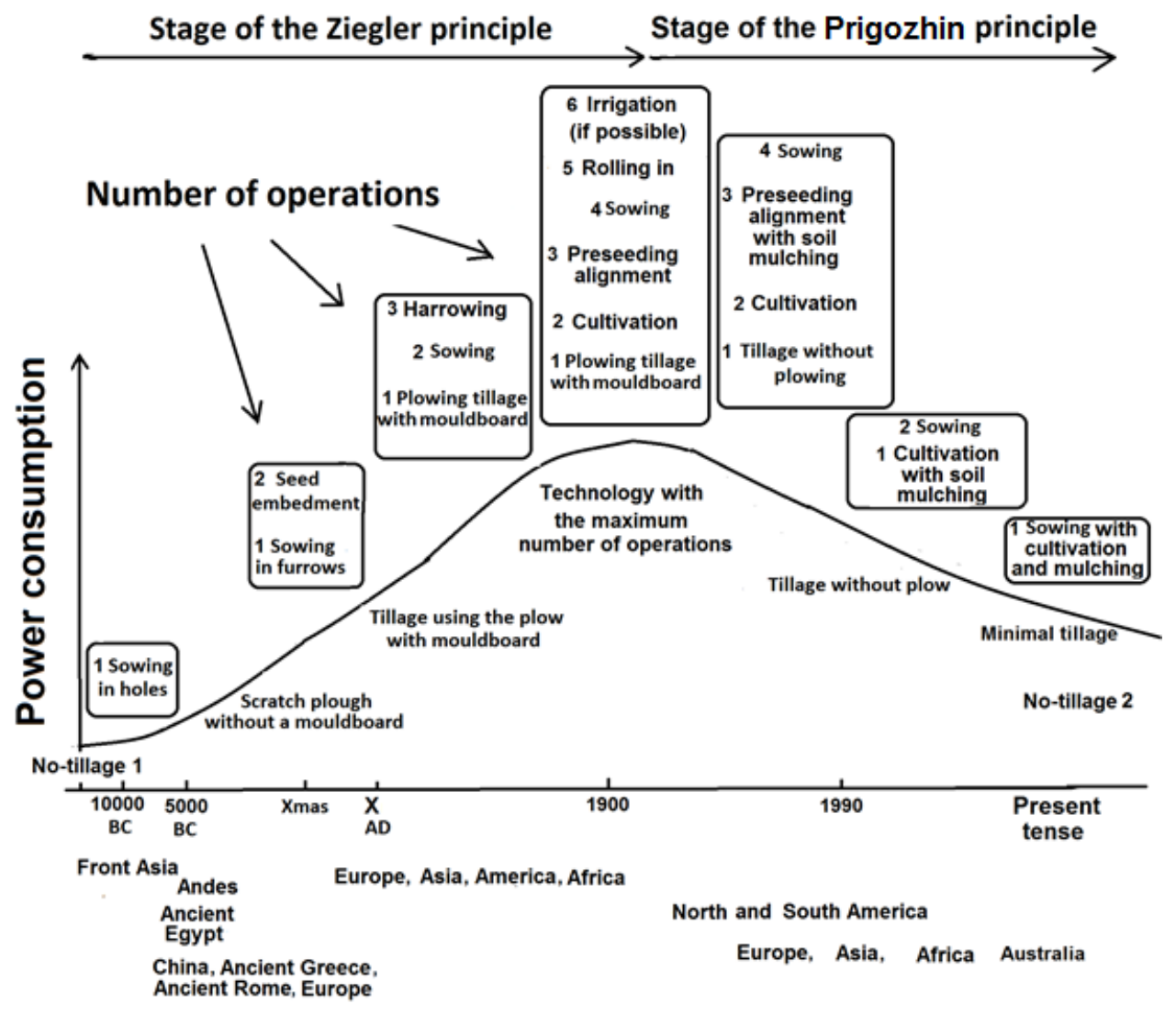

Fig. 4. Schematization of the evolution of soil cultivation technologies [20].

The goal of increasing production by means of extensive strategy (also including irrigation) has led to an increase in expenses. Irrigated agriculture has also evolved towards more consumption of energy. In contrast to their ancient predecessors (Fig. 2), modern irrigation systems include the creation of artificial canals, specific water intake systems, construction of an irrigation network, etc. [25] (Fig. 5).

But in the end, the considered trajectory of the evolution of farming technologies approached the moment when the priority of the Ziegler's principle changed to the priority of the Prigozhin's principle [21]. Human civilization found itself in a situation where huge amounts of energy are consumed for agricultural products, and labor costs for carrying out agrotechnical operations exceed all possible limits. 
In most cases, the soil condition in agricultural fields is assessed as poor or very poor: the top layer of the soil is loosened and turning into dust, at the same time, the layer below the plow sole is heavily compacted by the wheels and crawler bands of agricultural machines [6]. Arid regions are increasingly suffering from dust storms that carry away the fertile top soil layer, desertification and massive deforestation for agricultural land occurs, the processes of erosion and salinization of soils have significantly increased, the humus content in chernozems has decreased from 10-12 to 5-6\% [20].

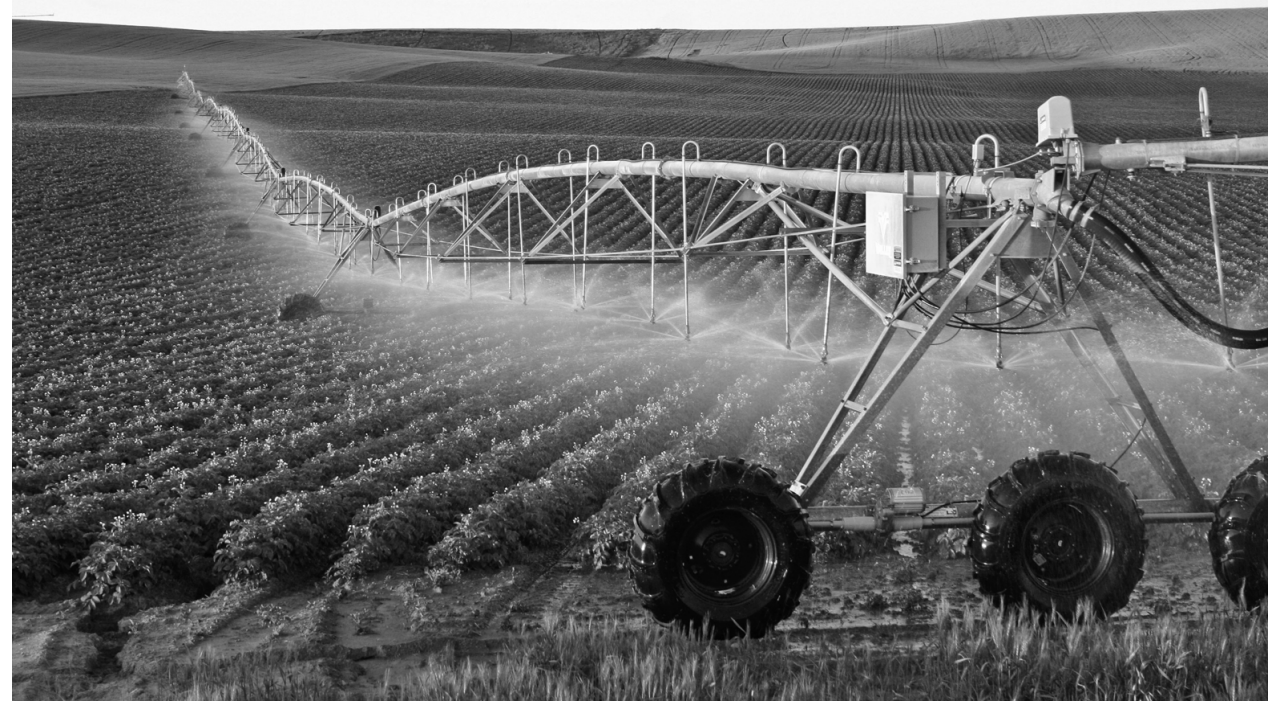

Fig. 5. An example of modern irrigation systems. Source: https://memim.com/irrigation.html Irrigation.

As a result, in order to preserve its homeostasis, following the physical laws of the dissipative structures evolution, the human population is doomed to the transition to the stage when the Prigozhin's principle of the minimum entropy production becomes the main governing physical law that determines the evolution of civilization, orienting the development of mankind towards the rational use of available resources. But, as shown in [21], this strategy leads to the inevitable emergence of a "green economy" [15, 23, 33, 37], the postulates of which are as follows: it is impossible to infinitely increase resources consumption in a limited area; it is impossible to demand satisfaction of evergrowing human needs under the conditions of limited resources; the principles and laws laid down by nature and have shown their effectiveness over millions of years of existence of the biosphere on Earth should become the basis for technologies for the use of natural resources.

The initial empirical understanding of the need for the transition of agriculture to technologies based on the use of natural or nature-like processes, criticism of plow tillage and rejection of deep plowing came in the 20th century. In Russia and the USSR, this understanding is associated with the names of such agronomical scientists as I.E. Ovsinsky, T.S. Maltsev, A.I. Baraev and others. In the United States, the development of no-till farming is associated with the name of E.H. Faulkner. Published in 1943, his book "The Plowman's folly" [16] immediately became a bestseller. It is with the publication of this 
book in the United States that the development of no-till, nature-like technologies in agriculture began.

The work of these researchers marked the beginning of a turn in agriculture towards the so-called non-traditional (soil protection, minimum, zero) tillage technologies (Fig. 4). The no-till system of soil cultivation is becoming a modern farming system (Fig. 6), in which the soil is practically not cultivated (sometimes a slight surface loosening is used), and its surface is covered with crushed plant residues - mulch, creating a "blanket" of crop residues on the soil.

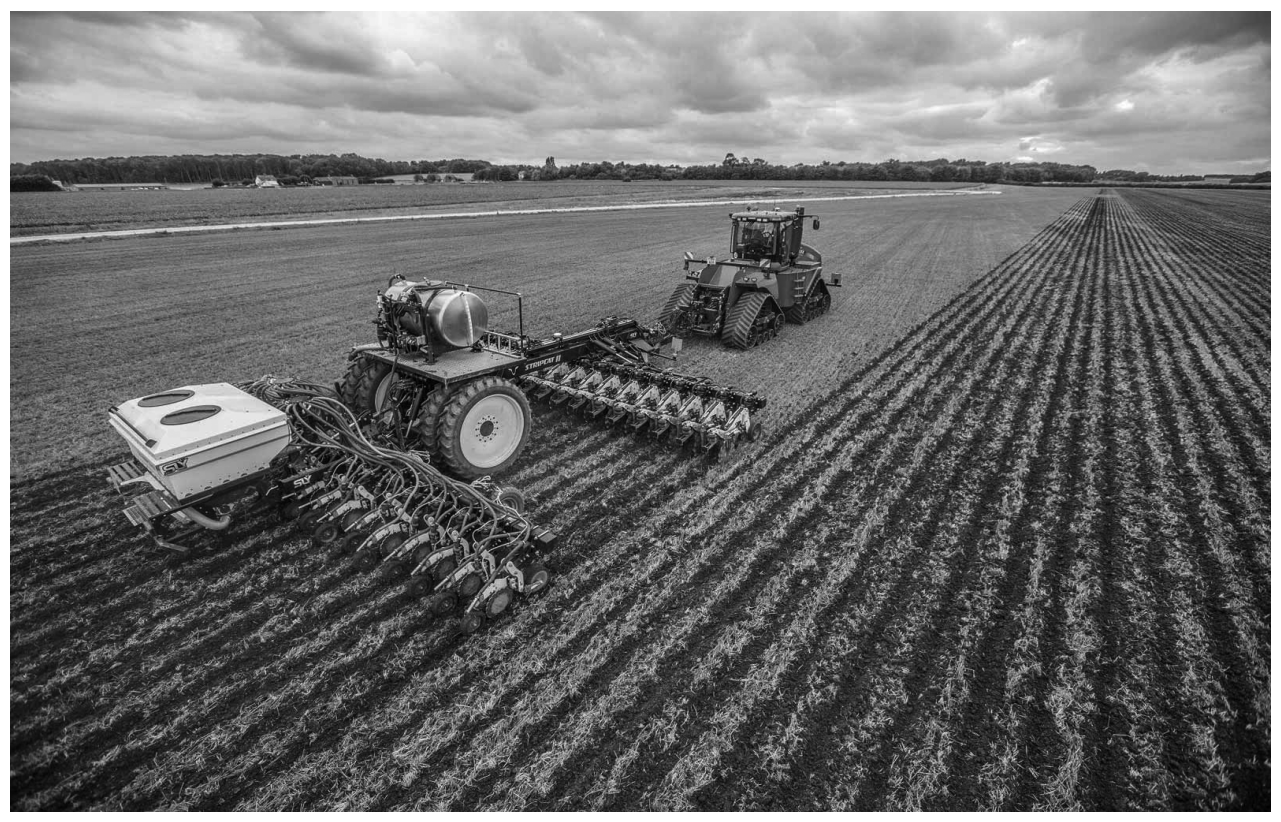

Fig. 6. Soil cultivation using no-till technology. Source: https://alfagro.com.ua/category/mnenieeksperta/

At the same time, the process of formation of an effective mulching layer from plant residues can last for several years. After the creation of mulch, the biocenosis in the soil is gradually restored and leads to the preservation of the carbon content in the soil and the reproduction of soil fertility [10]. At the same time, the ideal situation for the soil: intensive circulation of nutrients, significant carbon content, minimization of mineral fertilizers' use and almost complete elimination of soil erosion [5, 7, 28, 29] is achieved if no-till technologies are applied during $\sim 20$ years. Mulching cover contributes to the conservation of water resources by reducing the unproductive evaporation of water from bare soil [21, $22,36]$.

Sometimes strip-till is also used [26] as a compromise between classical and no-till tillage. With strip-till, the agricultural field is cultivated and sown in strips. At the same time, the rest of the field remains untouched and covered with a kind of mulch, which is the stubble of the previous crop.

Currently, no-till technology is used on a significant part of the land $[9,13,31]$ : from the Arctic Circle (Scandinavia), through the tropics (central Africa) to $50^{\circ}$ of south longitude (Falkland and Maldives). This technology has mainly become widespread on the American continent [12, 18, 34]: in Argentina, Paraguay, Uruguay, Canada, USA, Brazil, as well as in Australia and New Zealand [35]. In large grain producers such as Canada, Brazil and Argentina, more than half of all land is cultivated without plowing. 
In Europe, Asia and Africa, no-till technology is still used to a small extent. Currently in Russia, no-till technology is also fragmentarily used in Bashkortostan, Trans-Urals, Altai, Southern Siberia, and Crimea, showing quite decent results.

To some extent, the positive experience of using no-till technologies in different countries is shown in [20]. In Russia, due to the absence of many-year field research $(\sim 20$ -25 years) on the use of no-till technology, the effectiveness of its long-term use can only be assessed theoretically. For example, in [20, 21] for the steppe and forest-steppe zones of the European territory of Russia, a comparison was made between two strategies for the agriculture development in wheat production: (1) an increase in the average annual gross yield by increasing the share of irrigated land in the region to $10 \%$ [4], (2) obtaining the same wheat yield in the same territory due to the use of no-till technology on a part of the area with soil mulching with plant residues (irrigated areas do not increase in this case).

Theoretical estimates of the energy efficiency [20] of these two strategies (considering the statistical data for the region under consideration on the areas of arable land under wheat for each administrative unit of the region) showed that for the region the same wheat gross yields for the two strategies $\left(\sim 6.5 \cdot 10^{8} \mathrm{GJ} /\right.$ year, which is equivalent to a grain yield of 45 million tons/year) are achieved if for the second strategy $30 \%$ of arable land is used as no-till. At the same time, the energy costs for the second strategy are by $10^{8} \mathrm{GJ} /$ year less than for the first. If this difference expressed in the energy units is converted into the cost of the volume of oil (with the same energy content), then with the oil price assumed to be $\sim 50$ US\$ per barrel, the second strategy turns out in $\sim 1$ billion US\$/year cheaper than the first.

\section{Discussion}

The above brief analysis of the evolution of agrotechnical technologies that took place on Earth during the Holocene period confirms the conclusion arising from the theory of dissipative structures: at the present stage, the development of technologies for agriculture and the use of water resources related to agriculture, mankind has come to an inevitable change in technologies from extensive development and use of natural resources (energy, water, soil, etc.) to their rational use "green agriculture". And the point here is not that the human Mind has understood the prospects of such a turn of nature management technologies. As one of the most prominent cybernetics W.R. Ashby [8] noted, mind is not an absolutely positive property of organism that ensures its stability. As a remarkable element of adaptation, it works only in the conditions in which it originated. With a rapid change in the conditions of existence, organisms and species with a lower level of intelligence may well turn out to be more stable formations (as evidenced by the long-term evolution of life on Earth).

Second, the ability of the mind to consider an almost infinite number of interacting factors in the biosphere is also very limited $[1,2]$. It is impossible to replace the biotic regulation of the biosphere with regulation by the human mind (even with the help of artificial intelligence) - humanity cannot ensure the processing of information flows of such a volume that is available to natural biota [3]. At present, due to the presence of a huge number of "soft" negative feedbacks, Nature's strategy without Mind, due to the principle of I. Prigozhin, leads to a minimum of destructive processes on the planet as a whole. In this regard, the inevitability of the considered change of traditional technologies is determined simply by the laws of physics, in this case, by the laws of non-equilibrium thermodynamics.

Therefore, the turn of technologies noted and considered in the work began to occur first on an empirical (agronomic) basis. And only then scientific works related to the substantiation of its inevitability and, accordingly, with the inevitability of the transition from technospheric technologies of nature management to nature-like ones began to appear. 
Here, examples of nature-like technologies are the nature-based agrotechnology of minimal soil cultivation (without soil layers turnover which is unusual for the biosphere); mulching its surface with plant residues (analogue of the plant felt that is present in natural steppe ecosystems and prevents soil bareness unusual for nature, reduces its unproductive evaporation and erosion); minimization (by reducing the weight of agricultural machines and the frequency of their usage) of such a harmful effect for the soil as its densification associated with the impact of such a surprisingly effective achievement of "gray" technology as a wheel (Nature does not know the wheel); reducing the volume of such an aggressive method to the biosphere as irrigation which leads to disruption of the natural hydrological cycle of the land; reducing the use of "gray" technology associated with the use of herbicides and switching to the use of cover crops for weed control etc.

It should be noted that the development of nature-like technologies is largely due to advances in science obtained at the intersection of various scientific disciplines. At the previous stage of human development, the priority direction in science was the analysis of natural processes, which inevitably led to the formation of scientific thinking associated with the division of knowledge about Nature into many often completely unrelated scientific areas. They exist separately from each other, poorly reflecting the unity of Nature. (Nature knows no scientific disciplines). But now the stage of synthetic thinking has begun, both in science and in practice. If the XVII and XVIII centuries are often called the age of Newton (associated mainly with physics and mechanics) and the XIX century - the century of Darwin (development and evolution of living systems), then the XX century, as well as the beginning of the XXI century, can be considered as the century of V. Vernadsky (whose doctrine contributed to the view on the biosphere as a complex, but completely interconnected integral object). Therefore, the development of nature-like technologies (focused on the integrity of Nature), including in the field of agriculture, is the inevitability of future human interaction with the environment.

\section{Conclusion}

At the present stage of the Holocene, mankind found itself in a situation of the effect of the principle of I. Prigozhin - the situation of the need and inevitability of the rational use of available resources, in particular, in the field of agriculture and in the associated water sector. This circumstance inevitably leads to the use of the "green agriculture" strategy by mankind. This is manifested in the agriculture's transition from traditional, so-called "gray" technologies for natural resource management rigidly focused only on momentary economic feasibility, to non-traditional (nature-based, "green") technologies.

A kind of "experiment" set by the biosphere during the Holocene on the centuries-old evolution of agricultural technologies confirmed the above paradigm of the transition of human civilization to the methods and technologies of "green farming", which is illustrated by the current rapid development of no-till, strip-till, mulch-till technologies in different countries of the world. Evaluation of their effectiveness and ways to improve of agricultural technology, the development of new elements in the No-till system determine the further prospects for scientific research in the field of agriculture.

\section{Acknowledgements}

The work was carried out within the framework of topics No. 0126-2021-0001 (state registration No. 121040700170-9) "Development of a methodological base and digital technologies for supporting decision-making to ensure the water security of Crimea" and No. 0147-2018-0001 (state registration No. AAAA-A18- 118022090056-0) "Study and 
modeling of processes of the hydrological cycle of the land, hydrophysical and hydrodynamic processes, regularities of formation of surface, soil and groundwater resources in changing natural conditions."

\section{References}

1. V.G. Gorshkov, Physical and Biological Foundations of Life Sustainability, 470 (1995)

2. V.G. Gorshkov, K.Ya. Kondratyev, K.S. Losev, Ecology 3, 163-170 (1998)

3. V.I. Danilov-Danilyan, K.S. Losev, Environmental Challenge and Sustainable Development. Study aid. 416 (2000)

4. A.V. Kolganov, N.V. Sukhoy, V.N. Shkura, V.N. Shchedrin, Development of Agricultural Land Reclamation in Russia, 222 (2016)

5. Kh.M. Safin, L.S. Schvarts, R.S. Fakhrislamov, No-till technology in the system of conservation agriculture: theory and practice of implementation, 72 (2013)

6. A. Skuratovich, History of a great cause, 87-101 (2007)

7. No-till saves the farmer's land and money, https://apc-intech.ru/no-till-sberegaetpochvu-i-dengi-krestyanin

8. W.R. Ashby, Principles of the self-organizing system. In Principles of SelfOrganization, 255-278 (1962)

9. E. Balwinder-Singha, Humphreysb, D.S. Gaydond, P.L. Eberbachf, Field Crops Res. 197, 83-96 (2016) doi: 10.1016/j.fcr.2016.08.016.

10. C. Bayer, L. Martin-Neto, J. Mielniczuk, A. Pavinato, J. Dieckow, J Soil and Tillage Research, 86 (2), 237-245 (2006)

11. B. Commoner, The closing circle: Nature, man, a. technology, 326 (1971)

12. E. Creech, Saving Money, Time and Soil: The Economics of No-Till Farming, https://www.usda.gov/media/blog/2017/11/30/saving-money-time-and-soil-economicsno-till-farming

13. R. Derpsch, T. Friedrich, A. Kassam, L. Hongwen, Int J Agric\&Biol Eng., 3(1), $1-25$ (2010)

14. R.C. Dewar, Journal of Physics A: Mathematical and General.,38 (21), L371-L381 (2005) doi: 10.1088/0305-4470/38/21/101.

15. European Commission. Building a Green Infrastructure for Europe, 24 (2013) doi: $10.2779 / 54125$.

16. E.H. Faulkner,Plowman's Folly, 174 (1943)

17. C.E. Folsome, The Origin of Life, 82 (1979)

18. L.P. Gianessi, Croplife International, https://croplife.org/case-study/importance-ofherbicides-for-no-till-agriculture-in-south-america/

19. P. Glansdorff, I. Prigogine, Thermodynamic Theory of Structure, Stability and Fluctuations, 305 (1971)

20. E.M. Gusev, Arid Ecosystems, 10 (1), 1-9 (2020) doi: 10.1134/S2079096120010060.

21. E.M. Gusev, Arid Ecosystems, 9 (3), 143-149 (2019) doi: 10.1134/S2079096119030041. 
22. Y.M. Gusev, L.Y. Dzhogan, and O.N. Nasonova, Proc. Int. Assoc. Hydrol. Sci., 376, 77-82 (2018) doi: 10.5194/piahs-376-77-2018.

23. A. Hall, K. Dorai, The greening of agriculture. Agricultural innovation and sustainable growth, 60 (2010)

24. Introduction to Cover Crop Rolling \&The VA-USDA Crop Crimper Roller Demonstration Project. https://www.nrcs.usda.gov/Internet/FSE_DOCUMENTS/ nrcs142p2_018551.pdf

25. Irrigation, https://en.wikipedia.org/

26. I. Jaskulska, D. Jaskulski, Agronomy, 10, 925-942 (2020) doi:10.3390/agronomy10070925.

27. A. Kleidon, R.D. Lorenz (Eds.). Non-equilibrium Thermodynamics and the Production of Entropy: Life, Earth, and Beyond, 264 (2005)

28. D.R. Montgomery, GSA Today, 17(10), 4-9 (2007)

29. D.R. Montgomery, Dirt: Erosion of Civilizations, 296 (2007)

30. R.K. Niven, Physical Review E. 80 (2), $021113 \quad$ (2009) doi: 10.1103/physreve.80.021113.

31. No-Till Farming: Practices To Boost Agricultural Productivity, https://eos.com/blog/no-till-farming/

32. Organic No-till - The carbon pilgrim. https://carbonpilgrim.wordpress.com/2013/05 /14/organic-no-till/amp/

33. M.A. Palmer, J. Liu, J.H. Matthews, M. Mumba, P. D’Odorico, Science, 349 (6248), 384-385 (2015)

34. B. Plumer, No-till farming is on the rise. That's actually a big deal - via www.washingtonpost.com. https:/www.washingtonpost.com/news/wonk/wp/2013/1 1/09/no-till-farming-is-on-the-rise-thats-actually-a-big-deal/

35. F. Scott, Zero-till adoption soaring, NSW Government. https://www.dpi.nsw.gov.au/content/archive/agriculture-today-stories/ag-todayarchives/may-2010/zero-till-adoption-soaring

36. Sustainable Management of Water Resources in Agriculture, 120 (2010)

37. WWAP, Water. The United Nations World Water Development Report 2018: NatureBased Solutions for Water, 139 (Paris. UNESCO, 2018)

38. H. Ziegler, Progress in Solid Mechanics, 4, 91-198 (1963) 